\title{
A combined approach for comparative exoproteome analysis of Corynebacterium pseudotuberculosis
}

\author{
Luis GC Pacheco ${ }^{1,2,3}$, Susan E Slade ${ }^{4}$, Núbia Seyffert ${ }^{2}$, Anderson R Santos², Thiago LP Castro², Wanderson M Silva², \\ Agenor V Santos', Simone G Santos ${ }^{5}$, Luiz M Farias ${ }^{5}$, Maria AR Carvalho ${ }^{5}$, Adriano MC Pimenta ${ }^{1}$, Roberto Meyer ${ }^{3}$, \\ Artur Silva ${ }^{6}$, James H Scrivens ${ }^{4}$, Sérgio C Oliveira', Anderson Miyoshi ${ }^{2}$, Christopher G Dowson ${ }^{4}$, Vasco Azevedo ${ }^{2^{*}}$
}

\begin{abstract}
Background: Bacterial exported proteins represent key components of the host-pathogen interplay. Hence, we sought to implement a combined approach for characterizing the entire exoproteome of the pathogenic bacterium Corynebacterium pseudotuberculosis, the etiological agent of caseous lymphadenitis (CLA) in sheep and goats.

Results: An optimized protocol of three-phase partitioning (TPP) was used to obtain the C. pseudotuberculosis exoproteins, and a newly introduced method of data-independent MS acquisition (LC-MSE) was employed for protein identification and label-free quantification. Additionally, the recently developed tool SurfG+ was used for in silico prediction of sub-cellular localization of the identified proteins. In total, 93 different extracellular proteins of C. pseudotuberculosis were identified with high confidence by this strategy; 44 proteins were commonly identified in two different strains, isolated from distinct hosts, then composing a core C. pseudotuberculosis exoproteome. Analysis with the SurfG+ tool showed that more than 75\% (70/93) of the identified proteins could be predicted as containing signals for active exportation. Moreover, evidence could be found for probable non-classical export of most of the remaining proteins.

Conclusions: Comparative analyses of the exoproteomes of two C. pseudotuberculosis strains, in addition to comparison with other experimentally determined corynebacterial exoproteomes, were helpful to gain novel insights into the contribution of the exported proteins in the virulence of this bacterium. The results presented here compose the most comprehensive coverage of the exoproteome of a corynebacterial species so far.
\end{abstract}

\section{Background}

Corynebacterium pseudotuberculosis is a facultative intracellular pathogen that belongs to the so-called CMN (Corynebacterium-Mycobacterium-Nocardia) group, a distinct subgroup of the Actinobacteria that also includes other highly important bacterial pathogens, such as Corynebacterium diphtheriae and Mycobacterium tuberculosis. The most distinctive feature of these Gram-positive bacteria is the unique composition of the cell envelope, characterized by the presence of long

\footnotetext{
* Correspondence: vasco@icb.ufmg.br

${ }^{2}$ Department of General Biology, Instituto de Ciências Biológicas, Universidade Federal de Minas Gerais, Av. Antônio Carlos, Belo Horizonte, 31.270-901, Brazil

Full list of author information is available at the end of the article
}

chain fatty acids, known as mycolic acids, on the surface of the cell $[1,2]$.

The main recognizable disease caused by C. pseudotuberculosis is caseous lymphadenitis (CLA) in sheep and goats, though this bacterium can also infect several other hosts, including humans $[1,3]$. Typical manifestations of CLA in small ruminants include formation of abscesses in superficial and internal lymph nodes, and in visceral organs [3]. Despite the important economic losses caused by this disease to sheep and goat husbandry worldwide, no effective treatment exists, and the efficacy of the currently available vaccines and diagnostic methods is still controversial [4].

The search for C. pseudotuberculosis molecular determinants that contribute to CLA pathogenesis lead to the
C Biomed Central

() 2011 Pacheco et al; licensee BioMed Central Ltd. This is an Open Access article distributed under the terms of the Creative Commons Attribution License (http://creativecommons.org/licenses/by/2.0), which permits unrestricted use, distribution, and reproduction in any medium, provided the original work is properly cited. 
recognition of two exported proteins as the major virulence-associated factors of this bacterium known to date: a secreted phospholipase D (PLD) [5]; and an ABC-type transporter component of an iron uptake system (FagB) [6]. In fact, one might expect that the majority of the virulence determinants of $C$. pseudotuberculosis would be present in the exoproteome, i.e. the entire set of bacterial proteins found in the extracellular milieu [7]. This is because exported proteins participate in essential steps of the host-pathogen interplay, including: (i) adhesion to host cells; (ii) invasion; (iii) damage to host tissues; (iv) resistance to environmental stresses during infection; and (iv) subversion of the host's immune response mechanisms [8-10].

In two previous attempts to characterize the C. pseudotuberculosis exoproteome, our group optimized a protocol of salting out of proteins using sulfate and butanol, known as three-phase partitioning (TPP), for isolation of the extracellular proteins of this bacterium [11], and generated a library of C. pseudotuberculosis mutant strains possessing transposon insertions in genes coding for probable exported proteins [12]. In the former study, we were able to determine the optimal conditions for obtaining the best recovery of immunoreactive extracellular proteins of C. pseudotuberculosis [11]. The second study in turn, enabled us to identify various previously uncharacterized C. pseudotuberculosis exported proteins, being that at least two of them are apparently involved in virulence [12]. Now, the very recent conclusion of the $C$. pseudotuberculosis Genome Project by our group, associated to the current availability of high-throughput proteomic technologies, permitted us to perform a much more comprehensive analysis of this bacterium's exoproteome.

In this study, we sought to implement a combined approach for comparative exoproteome analysis of different C. pseudotuberculosis strains. The strategy included: (i) the previously optimized TPP protocol for isolation of the extracellular proteins [11]; (ii) a newly introduced method of data-independent LC-MS acquisition $\left(\mathrm{LC}-\mathrm{MS}^{\mathrm{E}}\right.$ ) for protein identification and quantification $[13,14]$; and (iii) the recently developed tool SurfG+ for in silico prediction of protein sub-cellular localization in Gram-positive bacteria [15]. We believe that the experimental approach used is very suitable for profiling bacterial exoproteomes, as it shown to be easily applicable to different strains with very good reproducibility. This is an advantage over what is commonly observed for proteomic approaches based on two-dimensional (2D) gel electrophoresis, where there is more variability, but is apparently the method of choice for most of the bacterial exoproteome studies published recently [16-20]. Furthermore, the LC-MS ${ }^{\mathrm{E}}$ method provides high subproteome coverage, due to enhanced sensitivity, and allows for label-free analysis of differentially expressed proteins [14]; this latter possibility enables the detection of variations in the exoproteomes of different strains that could be missed by simply profiling the exoproteins, and meets the growing interest in performing physiological proteomic studies of bacteria [21,22].

We were able to identify 93 different C. pseudotuberculosis extracellular proteins with high confidence by analyzing the exoproteomes of two strains isolated from different hosts that presented distinct virulence phenotypes under laboratory conditions $[23,24]$. Most of the identified proteins were predicted in silico to have an extracytoplasmic localization. To the best of our knowledge, these results compose the largest inventory of experimentally confirmed exoproteins of a single corynebacterial species to date. Importantly, the comparative exoproteome analyses permitted us to speculate on the probable contributions of different C. pseudotuberculosis extracellular proteins to the virulence of this bacterium.

\section{Results and Discussion}

\section{Exoproteome analysis of Corynebacterium} pseudotuberculosis

The extracellular proteins of two C. pseudotuberculosis strains, one isolated from a goat (strain 1002) the other from a sheep (strain C231), cultivated in a chemicallydefined medium, were extracted/concentrated by the TPP technique. The trypsinized protein samples were then submitted to LC-MS ${ }^{\mathrm{E}}$ analysis.

Seventy soluble extracellular proteins of the 1002 strain could be confidentially identified by this methodology, whereas the number of proteins identified in the exoproteome of the C231 strain was sixty-seven. Altogether, 93 different C. pseudotuberculosis exoproteins were identified in this study (Figure 1). These findings agree with the results of previous experiments by our group, in which we have used a 2D-PAGE based strategy for a preliminary appraisal of the C. pseudotuberculosis exoproteome (additional file 1). Eighty protein spots, mostly concentrated in the pI range between 3.0 and 6.0 , could be reproducibly visible in the $2 \mathrm{D}$ gels generated from TPP-extracted extracellular proteins of the 1002 strain (additional file 1). The fact that we have found 70 proteins in the exoproteome of this strain with high confidence when using the LC-MS ${ }^{\mathrm{E}}$ method (Figure 1) indicates that this novel methodology allowed us to identify virtually the complete set of extracellular proteins that are commonly observed in the gel based methodologies (additional file 1). Moreover, the expected existence of protein isoforms among the eighty protein spots observed in the $2 \mathrm{D}$ gels, and the identification by $\mathrm{LC}-\mathrm{MS}^{\mathrm{E}}$ of many proteins out of the $\mathrm{pI}$ range 3.0-6.0, suggests that the latter methodology is much more suitable for obtaining a comprehensive coverage of 


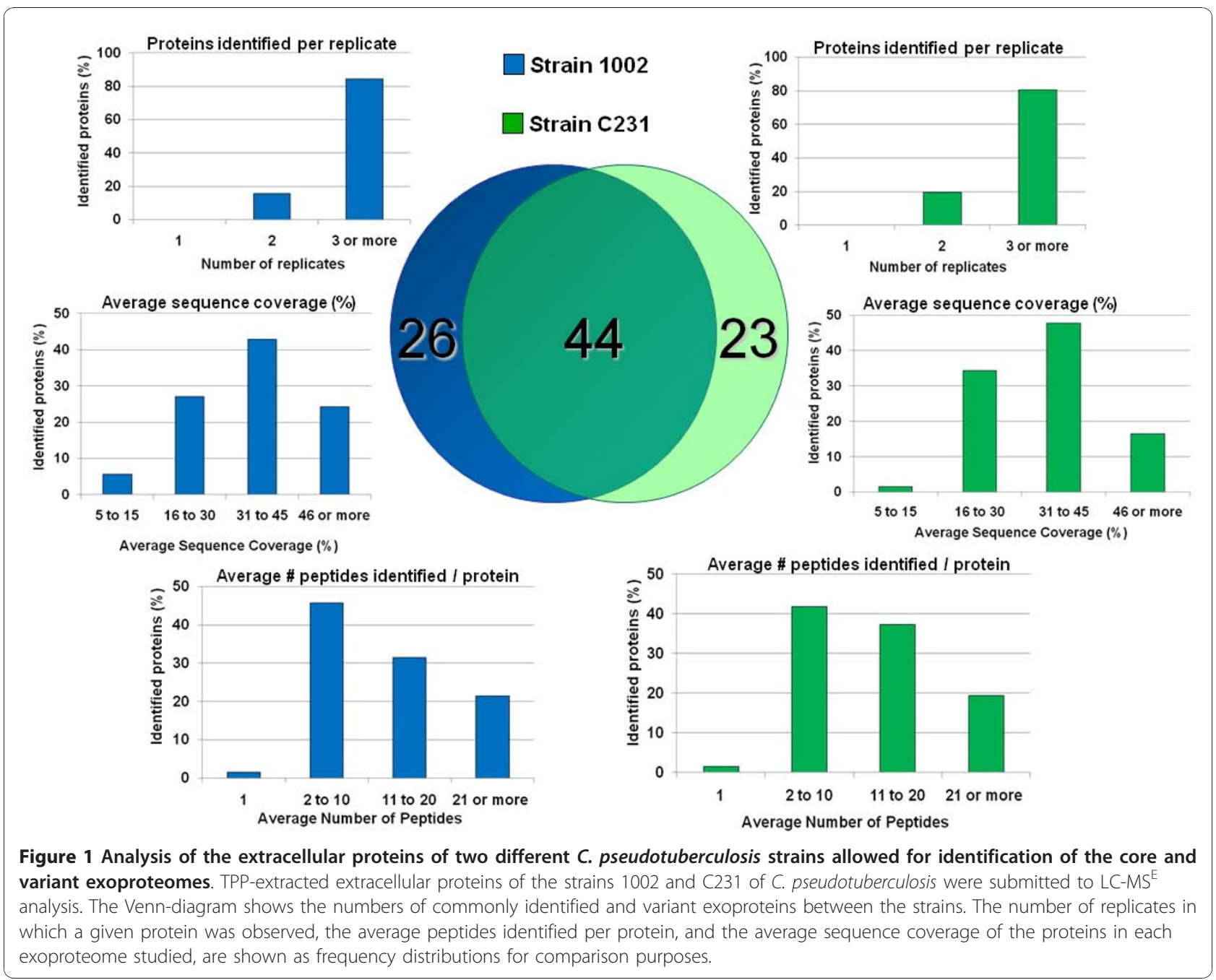

the bacterial exoproteome. Noteworthy, is the use of LC-MS ${ }^{\mathrm{E}}$ for exoproteome profiling which required (i) much less time and labor than the gel based proteomic strategy, and (ii) much less protein sample necessary for each experimental replicate, with only $0.5 \mu \mathrm{g}$ per replicate used in the $\mathrm{LC}-\mathrm{MS}^{\mathrm{E}}$ compared to $150 \mu \mathrm{g}$ for the 2D gels [refer to Patel et al. [25] for a comprehensive comparison on these proteomic strategies].

The performance of the combined methodology used in the present study (TPP/LC-MS ${ }^{\mathrm{E}}$ ) for mapping the C. pseudotuberculosis exoproteome was very similar for both strains analyzed, as can be seen by the average numbers of peptides observed per protein in the two proteomes (16.5 and 15.0) and by the average sequence coverage of the proteins identified (37.5\% and 35.0\%) (Figure 1). Consistent with this, the majority of the proteins detected in each extracellular proteome were shared by the goat and sheep isolates; this permitted us to define a core C. pseudotuberculosis exoproteome composed of 44 proteins out of the 93 different extracellular proteins identified. Additional files 2, 3 and 4 list all the proteins identified in the exoproteomes of the two C. pseudotuberculosis strains, along with molecular weights, isoelectric points, main orthologs, predicted sub-cellular localizations, number of peptides experimentally observed, and sequence coverage.

Searches of similarity against publicly available protein databases using the Blast-p tool [26] showed that ortholog proteins can be found in the pathogenic Corynebacterium diphtheriae for most of the identified C. pseudotuberculosis exoproteins (additional files 2, 3 and 4), as would be expected due to the close phylogenetic relationship of these species [27]. Nevertheless, no significant orthologs could be found for six proteins of the C. pseudotuberculosis exoproteome, even when using the position-specific iterated BLAST (PSI-BLAST) algorithm [28], namely the proteins [GenBank:ADL09626], [GenBank:ADL21925], [GenBank:ADL11253], [GenBank: ADL20222], [GenBank:ADL09871], and [GenBank: ADL21537] (additional files 2, 3 and 4). With the 
exception of [GenBank:ADL11253], all these proteins were predicted by different tools as being truly exported proteins. This means they are the only five exoproteins identified in this study which are probably unique for C. pseudotuberculosis.

\section{Prediction of sub-cellular localization of the identified proteins}

Most of the proteins identified in the exoproteomes of the two C. pseudotuberculosis strains were also predicted to have a probable extracytoplasmic localization after in silico analysis of the sequences of these proteins with different bioinformatics tools, thereby corroborating our in vitro findings (Figure 2, additional file 5). It is important to note here that we are considering the exoproteome as the entire set of proteins released by the bacteria into the extracellular milieu. That means we are looking to: (i) proteins possessing classical signals for active exportation by the different known mechanisms, which are directly secreted into the cell supernatant or that remain exposed in the bacterial cell surface and are eventually released in the growth medium [7]; and (ii) proteins exported by non-classical pathways, without recognizable signal peptides [29]. Besides, one might
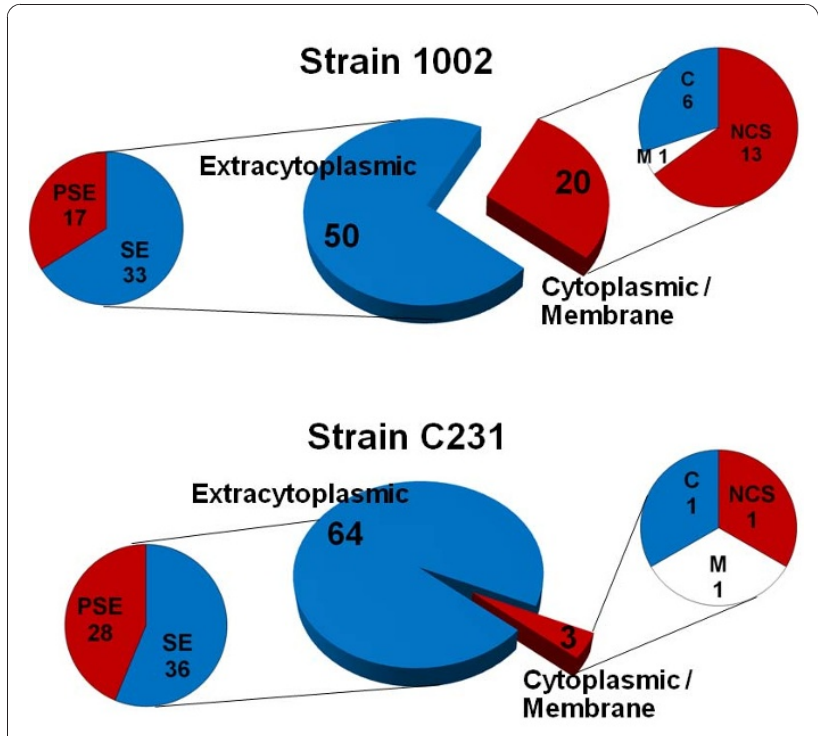

Figure 2 Most of the identified C. pseudotuberculosis exoproteins were predicted by the SurfG+ program as having an extracytoplasmic localization. The proteins identified in the exoproteomes of each C. pseudotuberculosis strain were analyzed by SurfG + and attributed a probable final sub-cellular localization. Proteins classified as having a cytoplasmic localization were further analyzed with the SecretomeP tool for prediction of non-classical (leaderless) secretion. Besides, literature evidence for exportation by non-classical pathways was also used to re-classify the cytoplasmic proteins (see text for details). SE = secreted; PSE = potentially surface exposed; $C=$ cytoplasmic; $M=$ membrane; $N C S=$ nonclassically secreted. also expect to observe in the extracellular proteome a small number of proteins primarily known to have cytoplasmic localization; although some of these proteins are believed to be originated from cell lysis or leakage, like in the extreme situation reported by Mastronunzio et al. [19], a growing body of evidence suggests that moonlighting proteins (in this case, cytoplasmic proteins that assume diverse functions in the extracellular space) may be commonly found in the bacterial exoproteomes [29-32].

By using the recently developed tool SurfG+ we were able to classify the identified C. pseudotuberculosis proteins into four different categories: (i) secreted, (ii) potentially surface exposed (PSE), (iii) membrane and (iv) cytoplasmic (Figure 2, additional files 2, 3 and 4). Basically, this software brings together the predictions of global protein localizations performed by a series of wellknown algorithms, and innovates by allowing for an accurate prediction of PSE proteins [15]. This possibility of classification provides us with valuable information on the proteins identified, as bacterial surface exposed proteins are believed to play important roles in the hostpathogen interactions during infection and many of these proteins have been shown to be highly protective when used in vaccine preparations [33,34].

From a total of 93 different $C$. pseudotuberculosis proteins identified in this study, 75\% (70) could be predicted as containing signals for active exportation (secretion or surface exposition) following SurfG+ analysis (Figure 2). Taken together, these proteins represent roughly $50 \%$ of all predicted secreted proteins in the recently sequenced genome of C. pseudotuberculosis, and around $15 \%$ of all predicted PSE proteins of this bacterium (A.R. Santos, pers. comm.).

The concordance of our in vitro identification of exoproteins with the in silico predictions of protein exportation is higher than what has normally been observed in recent exoproteome analyses of different bacteria [17-19,35,36]. For comparison, Hansmeier et al. [17] reported that exportation signals could be predicted in only $42(50 \%)$ out of 85 different proteins identified in the extracellular and cell surface proteomes of Corynebacterium diphtheriae. The authors of this study are not the only to speculate on a probably important contribution of cross-contamination of the protein sample during preparation procedures for the observation of high numbers of proteins not predicted as having extracellular location in the bacterial exoproteomes [17,31]. We believe that the proportionally higher identification of proteins possessing exportation signals in the present study could have happened due to a series of different factors, including: (i) our methodology for isolation of the bacterial extracellular proteins might have extracted less "contaminant" cytoplasmic proteins than did other 
methodologies reported in previous studies; (ii) the combined strategy used by SurfG + to predict protein sub-cellular localization might have performed better in the identification of exported proteins than happened with other strategies, sometimes based in only one prediction tool; (iii) the fact that we have included in the final exoproteome lists only proteins identified with high confidence, in at least two experimental replicates, reduced significantly the possibilities of false-positive identifications that might account for some of the unexpected proteins; and finally (iv) the lower proportion of proteins primarily regarded as cytoplasmic might be actually a typical characteristic of the C. pseudotuberculosis exoproteome.

\section{Non-classically secreted proteins}

Intriguingly, a much higher proportion $(29.0 \%)$ of the exoproteome of the 1002 strain of C. pseudotuberculosis was composed by proteins predicted by SurfG+ as not having an extracytoplasmic location, when compared to only $4.5 \%$ in the exoproteome of the strain C231 (Figure 2). The possibility of these proteins being non-classically secreted has been evaluated using the SecretomeP algorithm [29]. We have also reviewed the literature for evidence of other bacterial exoproteomes that could support the extracellular localization found for these proteins in our study.

High SecP scores (above 0.5 ) could be predicted for 5 of the 19 proteins in the exoproteome of the 1002 strain considered by SurfG + as having a cytoplasmic location (additional files 2 and 3); this could be an indicative that they are actually being secreted by non-classical mechanisms [29]. Nonetheless, 2 of these 5 proteins ([GenBank:ADL09626] and [GenBank:ADL20555]) were also detected in the exoproteome of the C231 strain, in which they were predicted by SurfG+ as possessing an extracytoplasmic location (additional file 2). A comparative analysis of the sequences encoding these proteins in the genomes of the two C. pseudotuberculosis strains showed that the disparate results were generated due to the existence of nonsense mutations in the genome sequence of the 1002 strain, which impaired the identification of signal peptides for the two proteins at the time of SurfG+ analysis (data not shown). We believe that it is unlikely that these differences represent true polymorphisms, as the proteins were identified in the extracellular proteome, indicating the real existence of exportation signals. This indeed demonstrates the obvious vulnerability of the prediction tools to the proper annotation of the bacterial genomes. On the other hand, the assignment of high SecP scores to these two proteins, even though they are not believed to be secreted by non-classical mechanisms, would be totally expected, as the SecretomeP is a predictor based on a neural network trained to identify general features of extracellular proteins; this means the prediction tool will attribute SecP scores higher than 0.5 to most of the secreted proteins, regardless the route of export [29].

We have found reports in the literature that strongly support the extracellular localization observed for 8 of the 14 remaining proteins considered as non-secretory by SurfG+ and SecretomeP in the exoproteome of the 1002 strain, and without any detectable signal peptide (additional files 2 and 3, Figure 2). Among these proteins there are the elongation factors $\mathrm{Tu}$ and $\mathrm{Ts}[16,33$, 35,37-39]; the glycolytic enzymes triosephosphate isomerase, phosphoglycerate kinase and phosphoglycerate mutase [16-20,37-40]; the chaperonin GroES [16-18, 20,39]; a putative peptidyl prolyl cis trans isomerase $[17,18,35,37,41]$; and a hydroperoxide reductase enzyme $[17,35,39]$.

Proteins primarily regarded as cytoplasmic have consistently been identified in the exoproteomes of different bacterial species, and moonlighting roles in the extracellular environment have already been demonstrated for some of them [31,32], including evasion of host's immune system [42], adhesion to host cells [43,44], folding of extracytoplasmic proteins $[41,45]$, and interaction between microorganisms $[40,46]$. Noteworthy, specific evidences for active secretion of such cytoplasmic proteins have been demonstrated for only a few examples to date, and demonstration of an extracellular function is still missing for many of these proteins [30,31].

\section{The variant exoproteome may account for differential virulence of the two C. pseudotuberculosis strains}

A considerable number (49/93) of the extracellular proteins identified in this work was observed in only one of the two strains studied, then composing a variant experimental C. pseudotuberculosis exoproteome (additional files 3 and 4). Highly variant exoproteomes have also been reported recently for other Gram + bacterial pathogens [20,36,39,47-49], and such a variation may be considered an important factor leading to the observable phenotypic dissimilarities and ultimately to differential virulence of the various strains [50,51]. Hecker et al. [36] reported on how the composition of the exoproteome can vary extremely within a single species, Staphylococcus aureus, being that only 7 out of 63 identified extracellular proteins were found in all the twenty-five clinical isolates studied.

One of the most intriguing results in the present study was the detection of the phospholipase D (PLD) protein only in the extracellular proteome of the strain C231 (additional file 4). As the regulation of PLD expression was demonstrated to be complex and highly affected by multiple environmental factors [52], we sought to detect this protein in the culture supernatant of the 
C. pseudotuberculosis 1002 strain grown in a rich medium (brain-heart infusion broth) instead of only chemically-defined medium (CDM), but these attempts were also unfruitful (data not shown). Besides, we were not able to detect secretion of PLD following total exoproteome analysis of the 1002 strain grown under specific stress generating conditions (Pacheco et al., unpublished). The results strongly indicate that this protein is actually not being secreted by the 1002 strain in culture.

PLD is an exotoxin considered as the major virulence factor of C. pseudotuberculosis [5,52]. It possesses sphingomyelinase activity that contributes to endothelial permeability and then to spreading of the bacteria within the host [5]. Mutation of the pld gene in C. pseudotuberculosis rendered strains no longer capable of causing caseous lymphadenitis (CLA) in sheep and goats; the potential of these strains to be used as live attenuated vaccines was already evaluated [53-55]. Similarly, the strain 1002 of C. pseudotuberculosis was already tested as a possible live attenuated vaccine against CLA due to its natural low virulent status, and administration of this bacterium to goats did not cause lesions formation [23,56]. The molecular mechanisms leading to the low virulence of the 1002 strain however remain undetermined so far. We believe that non-secretion of PLD might be one of the main factors responsible for the lowered virulence of the strain. Importantly, we currently cannot affirm that the 1002 strain does not produce this protein while infecting a mammalian host. Besides, this strain still retains the capability of causing localized abscesses and disease in susceptible mice (Pacheco et al., unpublished results).

Other proteins believed to be associated with the virulence of $C$. pseudotuberculosis were also identified exclusively in the exoproteome of the C231 strain, namely FagD and $\mathrm{Cp} 40$ (Table 1 ). The former protein is a component of an iron uptake system, whose coding sequences are clustered immediately downstream of the pld gene in the C. pseudotuberculosis genome [6]. The latter protein is a secreted serine protease shown to be protective against CLA when used to vaccinate sheep [57].

Strikingly, one variant protein of the C. pseudotuberculosis exoproteome, a conserved hypothetical exported protein with a cutinase domain [GenBank:ADL10384], has its coding sequence present in the genome of the C231 strain but absent from the genome of the 1002 strain (additional file 6). The genomic structure of the gene's surroundings is indicative of a region prone to recombination events, such as horizontal gene transfer [58]. In fact, it seems that gene gain and loss are frequent events leading to variations observed in the bacterial exoproteomes [39,59].
Variation of the core exoproteome: differential expression analysis of the common proteins by LC-MS ${ }^{\mathrm{E}}$

In addition to identifying qualitative variations in the exoproteomes of the two C. pseudotuberculosis strains, we were also able to detect relative differences in expression of the proteins common to the two proteomes through label-free protein quantification by the $\mathrm{LC}-\mathrm{MS}^{\mathrm{E}}$ method. Relative protein quantification by this method can be obtained with basis on the accurate precursor ion mass and electrospray intensity data, acquired during the low energy scan step of the alternating scan mode of MS acquisition [14]. Importantly, this quantitative attribute of the technique opens up new possibilities of utilization, as grows the interest on the so-called physiological proteomics [21].

Thirty-four out of 44 proteins commonly identified in the exoproteomes of the strains 1002 and C231 of C. pseudotuberculosis were considered by the PLGS quantification algorithm as having significantly variable expression (score > 250; 95\% CI) (Figure 3, additional files 2 and 7). If we further filter these results for the proteins presenting differential expression higher than 2 -fold between the strains, we end up with only four proteins up-regulated in the 1002 strain and sixteen in the C231 strain (Figure 3).

Among the group of proteins not presenting considerable variations in expression between the two C. pseudotuberculosis strains, proteins probably participating in basic bacterial physiological processes could be easily identified, as would be expected, including cell shape maintenance and cell division (penicillin binding protein, transglycosylases, peptidases, PGRP amidase) [60]; and iron uptake and utilization (HmuT) [61] (Figure 3, additional file 2). In this sense, one might also speculate that the hypothetical proteins identified as non variant in the two strains may have functions associated to the general physiology of $C$. pseudotuberculosis, when grown in minimal medium.

The most up-regulated proteins were observed in the extracellular proteome of the C231 strain, including two cell envelope-associated proteins [62], namely the major secreted (mycoloyltransferase) protein PS1 (10-fold upregulated), and the S-layer protein A (8-fold up-regulation) (Figure 3). This may be indicative of differences on cell envelope-related activities in the two C. pseudotuberculosis strains, such as nutrient acquisition, protein export, adherence and interaction with the host [63]. Dumas et al. [49] compared the exoproteomes of Listeria monocytogenes strains of different virulence groups, and found that altered expression (up- or down-regulation) of a protein related to the bacterial cell wall could be a marker of specific virulence phenotypes. Additionally, surface associated proteins have been shown to undergo phase and antigenic variation in some bacterial 
Table 1 Formerly and newly identified ${ }^{\ddagger}$ exported proteins that may be associated with the virulence phenotype of Corynebacterium pseudotuberculosis strains

\begin{tabular}{|c|c|c|c|c|c|c|}
\hline \multirow[t]{2}{*}{ Protein Description $^{a}$} & \multirow[t]{2}{*}{ GenBank Accession } & \multicolumn{2}{|c|}{$\begin{array}{l}\text { Identified in the } \\
\text { exoproteome of } \\
\text { the strain }{ }^{\mathrm{b}} \text { : }\end{array}$} & \multicolumn{2}{|c|}{$\begin{array}{l}\text { Orhologs found in other } \\
\text { Corynebacteriac: }\end{array}$} & \multirow[t]{2}{*}{ References } \\
\hline & & 1002 & C231 & Pathogenic & Non-pathogenic & \\
\hline Phospholipase D (PLD) & ADL09524.1 & No & Yes & Yes & No & [54] \\
\hline Iron siderophore binding protein (FagD) & ADL09528.1 & No & Yes & Yes & Yes & [6] \\
\hline Serine proteinase precursor (CP40) & ADL11339.1 & No & Yes & No & No & [57] \\
\hline Putative iron transport system binding (secreted) protein & ADL10460.1 & No & Yes & Yes & No & {$[12]$} \\
\hline Glycerophosphoryl diester phosphodiesterase & ADL11410.1 & No & Yes & Yes & No & This work. [72] \\
\hline Putative surface-anchored membrane protein & ADL20074.1 & Yes & Yes & Yes & No & This work. \\
\hline Putative hydrolase (lysozyme-like) & ADL20788.1 & Yes & Yes & Yes & No & This work. \\
\hline Putative secreted protein & ADL21714.1 & Yes & Yes & Yes & No & This work. \\
\hline Putative sugar-binding secreted protein & ADL09872.1 & No & Yes & Yes & No & This work. \\
\hline
\end{tabular}

pathogens, and ultimately affect the infectivity potential of different strains [50].

\section{Comparative analyses of corynebacterial exoproteomes}

Recent studies attempted to characterize the extracellular proteomes of other pathogenic ( $C$. diphtheriae and C. jeikeium) and non-pathogenic (C. glutamicum and C. efficiens) corynebacterial species [17,37,64,65]. All these studies used 2D-PAGE to resolve the extracellular

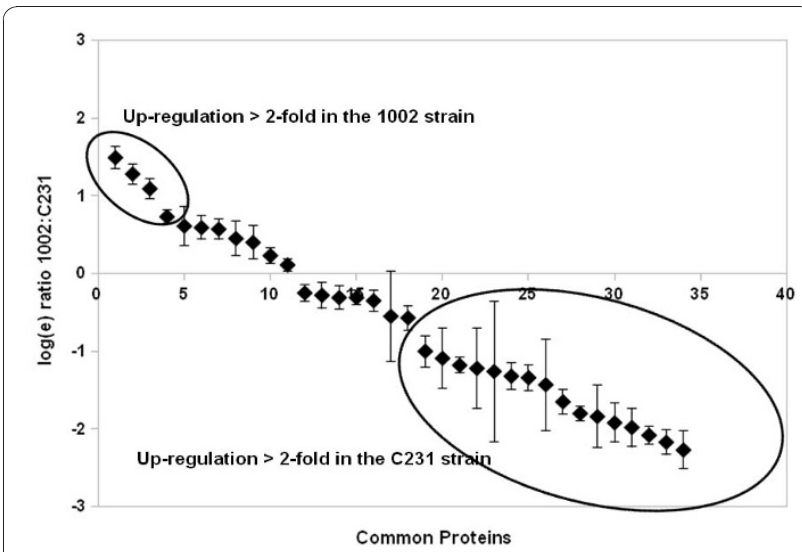

Figure 3 Differential expression of the proteins composing the core $C$. pseudotuberculosis exoproteome, evaluated by labelfree relative quantification using $\mathrm{LC}-\mathrm{MS}^{\mathrm{E}}$. Results are shown as natural log scale of the relative quantifications (1002:C231) for each protein. Only proteins that were given a variation score higher than 250 by PLGS quantification algorithm are presented. Proteins regulated more than 2 -fold in each strain are indicated. Protein identification numbers correspond to additional files 2 and 7: Tables S1 and S4. proteins of the different corynebacteria, and PMF by MALDI-TOF-MS was the method of choice in most of them for protein identification $[17,37,64,65]$. Figure 4 shows the numbers of proteins identified in the exoproteomes of all strains studied, in comparison to the numbers obtained in the present study for C. pseudotuberculosis. Despite one study with the strain R of C. glutamicum, which reports identification of only two secreted proteins [65], all the corynebacterial strains had somehow similar numbers of extracellular proteins identified, ranging from forty-seven in C. jeikeium K411 to seventy-four in $C$. diphtheriae $\mathrm{C} 7 \mathrm{~s}(-)^{\text {tox- }}$. Importantly, the fact that we have identified in this study 93 different exoproteins of $C$. pseudotuberculosis, through the analysis of two different strains, means that our dataset represents the most comprehensive exoproteome analysis of a corynebacterial species so far.

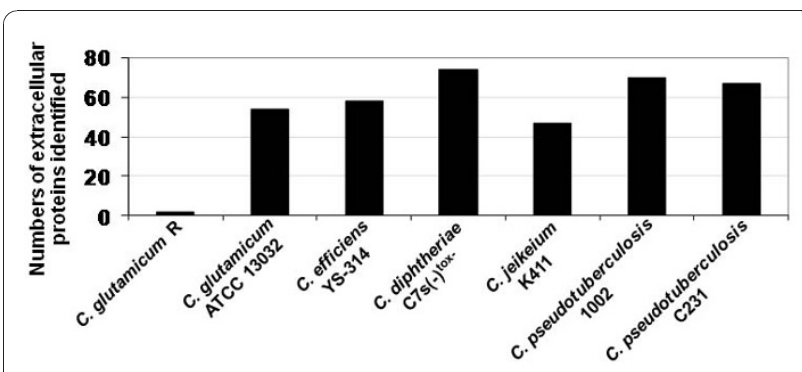

Figure 4 Comparative analysis of corynebacterial exoproteomes Numbers of extracellular proteins identified in previous corynebacterial exoproteome analyses $[17,37,69,70]$ in comparison to those identified in this study with the two strains of C. pseudotuberculosis. 
Regardless the different methodologies employed to characterize the exoproteomes of the various corynebacteria, we sought to identify extracellular proteins commonly identified in most of the studies, taking the catalogue of C. pseudotuberculosis exoproteins generated in this work as the comparison dataset. Besides corroborating our findings, the objective here was to identify extracellular proteins that could be associated exclusively to pathogenic corynebacterial species.

In total, 34 proteins identified in the exoproteome of the strain 1002 of C. pseudotuberculosis were found to be present in the experimentally determined extracellular proteomes of other corynebacteria, whereas the number of common corynebacterial exoproteins in the C231 strain was 32 (Figure 5). Only 6 proteins were consistently identified in all the corynebacterial exoproteomes, including pathogenic and non-pathogenic species: (i) S-layer protein A [62]; (ii) resuscitation-promoting factor RpfB [66]; (iii) cytochrome c oxidase subunit II [67]; (iv) a putative esterase; (v) a NLP/P60 family protein (putative cell wall-associated hydrolase) [68]; and (vi) a trehalose corynomycolyl transferase (Figure 5, additional file 8). Interestingly, three of these six proteins are predicted to be regulated by the same transcription factor [GenBank:ADL09702], a member of the cAMP receptor protein (Crp) family of transcription regulators which are found controlling a diversity of physiological functions in various bacteria [69].

Twelve proteins of the exoproteome of the 1002 strain and fifteen of the C231 strain were also detected experimentally only in the exoproteomes of other pathogenic corynebacteria, namely $C$. diphtheriae and $C$. jeikeium (Figure 5). Altogether, this represents 19 different C. pseudotuberculosis proteins (additional file 8). A search of similarity using the sequences of these proteins against publicly available databases, believed to contain the predicted proteomes of all corynebacteria with completely sequenced genomes, showed that 6 of these

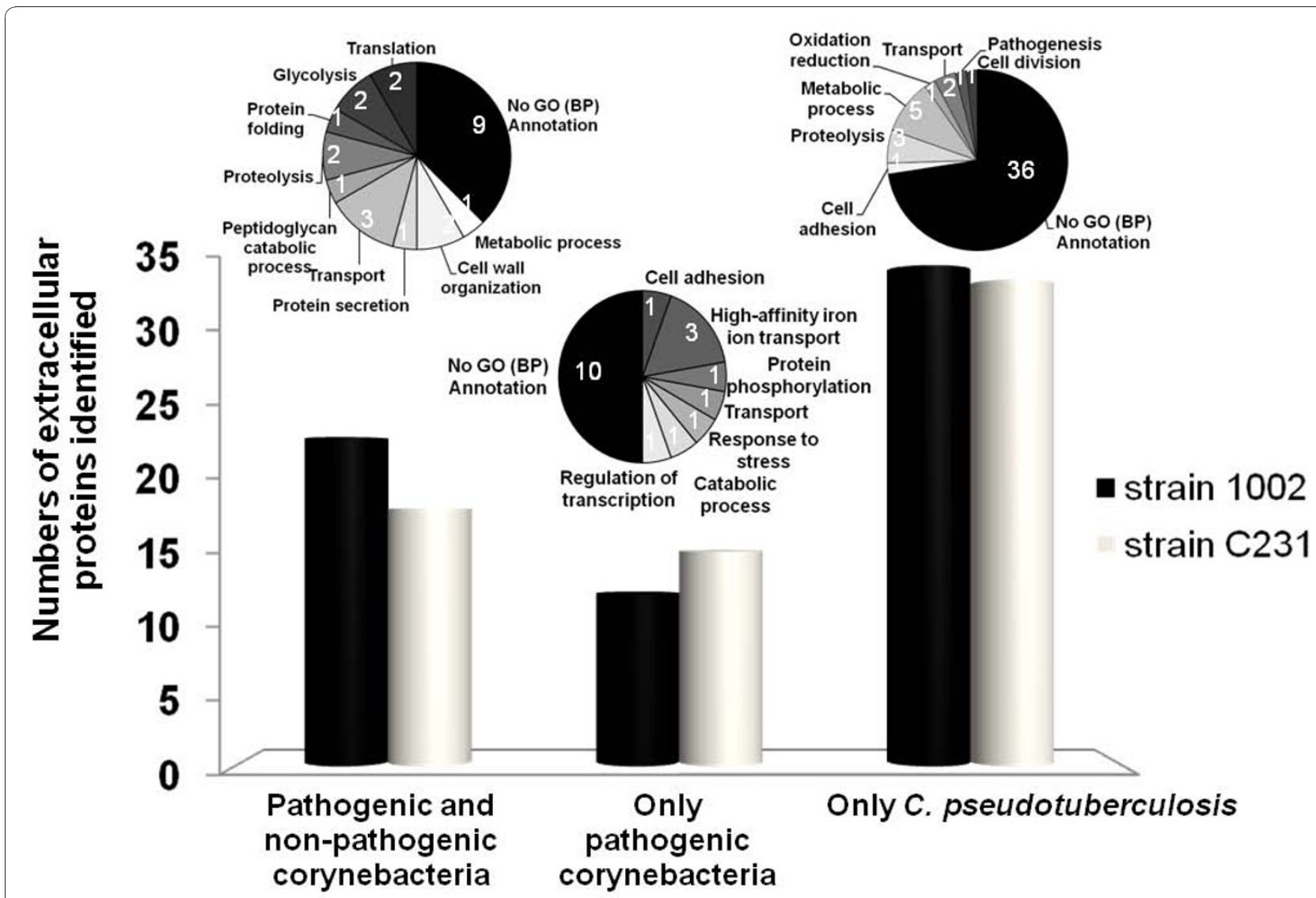

Figure 5 Distribution of orthologous proteins of the $C$. pseudotuberculosis experimental exoproteins throughout other experimentally confirmed corynebacterial exoproteomes. Pathogenic species: C. diphtheriae C7s(- $)^{\text {tox- }}$ and C. jeikeium K411 [17,69]; non-pathogenic species: C. glutamicum ATCC13032 and C. efficiens YS-314 [37,70]. Pie charts show Gene Ontology (GO) functional annotations for the 93 different C. pseudotuberculosis exoproteins identified (24 commonly identified in pathogenic and non-pathogenic corynebacteria; 19 commonly identified only in pathogenic corynebacteria; and 50 only identified in C. pseudotuberculosis). Annotations were obtained following analyses with the Blast2GO tool [84], used through the web application available at http://www.blast2go.org/start_blast2go. 
19 proteins are apparently absent from non-pathogenic corynebacterial species (Table 1). Moreover, 5 of these proteins are predicted to be part of regulatory networks already shown to be involved in virulence functions, including those regulated by the diphtheria toxin repressor (DtxR)-like protein [70] and the cAMP-binding transcription regulator GlxR [71].

Two proteins presented orthologs highly distributed in various bacterial pathogens: (i) a putative iron transport system binding (secreted) protein [GenBank:ADL10460]; and (ii) a putative glycerophosphoryl diester phosphodiesterase [GenBank:ADL11410]. Interestingly, an ortho$\log$ of this latter protein was included recently in a list of seventeen proteins found to be very common in pathogenic bacteria and absent or very uncommon in nonpathogens, representing then probable virulence-associated factors [72]. In fact, reports in the literature can be found that associate orthologs of the two aforementioned proteins with virulence phenotypes $[73,74]$. Noteworthy, both proteins were detected in this study only in the exoproteome of the C231 strain of C. pseudotuberculosis, the more virulent one.

\section{Conclusions}

There seems to be a growing interest in profiling the exoproteomes of bacterial pathogens, due to the distinguished roles played by exported proteins on hostpathogen interactions [10]. Classical proteomic profiling strategies, normally involving two-dimensional (2D) gel electrophoresis, have been extensively used for this purpose [16-20]. Nevertheless, the introduction of more high-throughput proteomic technologies brings new perspectives to the study of bacterial exoproteomes, as it makes it easier to analyze multiple phenotypically distinct strains, yielding better subproteome coverage with fewer concerns regarding technical sensitivity and reproducibility [75]. Besides, the currently available methods for label-free quantification of proteins [76] allow us to compare the "dynamic behavior" of the exoproteome across different bacterial strains, and this in turn will help us to better identify alterations of the exoproteome that may contribute to the various virulence phenotypes.

By using a high-throughput proteomic strategy, based on a recently introduced method of LC-MS acquisition $\left(\mathrm{LC}-\mathrm{MS}^{\mathrm{E}}\right)$ [14], we were able to perform a very comprehensive analysis of the exoproteome of an important veterinary pathogen, Corynebacterium pseudotuberculosis. Comparative exoproteome analysis of two strains presenting different virulence status allowed us to detect considerable variations of the core C. pseudotuberculosis extracellular proteome, and thereby the number of exoproteins identified increased significantly. Most importantly, it was helpful to gain new insights into the probable participation of C. pseudotuberculosis exported proteins, other than the well-known PLD and FagB, in the virulence of this bacterium. Several novel targets for future work on C. pseudotuberculosis molecular determinants of virulence can be identified from the catalogue of exoproteins generated in this study. Interestingly, around $30 \%$ of the proteins identified were predicted by the SurfG+ software [15] as being probably surface exposed in C. pseudotuberculosis. Such proteins may represent promising new candidates for composing a CLA vaccine more effective than the ones currently available [4], as has been demonstrated for a series of other bacterial pathogens $[33,34]$. Therefore, it will be critical to further study the role of this protein set in virulence and vaccine design.

\section{Methods}

\section{Bacterial strains and culture conditions}

The strains 1002 and C231 of Corynebacterium pseudotuberculosis were used in this study. Strain 1002 was isolated from an infected goat in Brazil and has been shown to be naturally low virulent $[23,56]$; strain C231 was isolated from an infected sheep in Australia, and it showed a more virulent phenotype [24]. Species confirmation was performed by biochemical and molecular methods for both strains, as described [77]. Complete genome sequences of the two strains were generated by Genome Networks in Brazil and Australia (RGMG/ RPGP and CSIRO Livestock Industries), and made available for this study (unpublished results).

C. pseudotuberculosis strains were routinely maintained in Brain Heart Infusion broth (BHI: Oxoid, Hampshire, $\mathrm{UK}$ ) or in $\mathrm{BHI} 1.5 \%$ bacteriological agar plates, at $37^{\circ} \mathrm{C}$. For proteomic studies, strains were grown in a chemically defined medium (CDM) previously optimized for $C$. pseudotuberculosis cultivation [78]. The composition of the CDM was as follows: autoclaved $0.067 \mathrm{M}$ phosphate buffer $\left[\mathrm{Na}_{2} \mathrm{HPO}_{4} \cdot 7 \mathrm{H}_{2} \mathrm{O}(12.93 \mathrm{~g} / \mathrm{L}), \mathrm{KH}_{2} \mathrm{PO}_{4}(2.55 \mathrm{~g} / \mathrm{L})\right.$, $\mathrm{NH}_{4} \mathrm{Cl}(1 \mathrm{~g} / \mathrm{L}), \mathrm{MgSO}_{4} \cdot 7 \mathrm{H}_{2} \mathrm{O}(0.20 \mathrm{~g} / \mathrm{L}), \mathrm{CaCl}_{2}(0.02 \mathrm{~g} /$ $\mathrm{L})$, and $0.05 \%(\mathrm{v} / \mathrm{v})$ Tween 80$]$; 4\% (v/v) MEM Vitamins Solution 100X (Invitrogen); 1\% (v/v) MEM Amino Acids Solution 50X (Invitrogen); 1\% (v/v) MEM Non Essential Amino Acids Solution 100X (Invitrogen); and 1.2\% (w/v) filter-sterilized glucose.

\section{Three-phase partitioning}

Extraction/concentration of the soluble supernatant proteins of C. pseudotuberculosis followed the TPP protocol previously optimized by our group [11], with minor modifications. Briefly, overnight cultures (ca. 24 hours) of the different $C$. pseudotuberculosis strains were inoculated (1:100) separately into $500 \mathrm{~mL}$ of pre-warmed fresh $\mathrm{CDM}$ and incubated at $37^{\circ} \mathrm{C}$, with agitation at 100 rpm, until reach the mid-exponential growth phase $\left(\mathrm{OD}_{540 \mathrm{~nm}}=0.4\right.$; LabSystems iEMS Absorbance Plate 
Reader). At this point, cultures were centrifuged at room temperature (RT) for $20 \mathrm{~min}, 4000 \mathrm{rpm}$, and $400 \mathrm{~mL}$ of each supernatant was transferred into new sterile flaks. Following addition of $20 \mu \mathrm{L}$ Protease Inhibitor Cocktail P8465 (Sigma-Aldrich), supernatants were filtered through $0.22 \mu \mathrm{m}$ filters; ammonium sulphate was added to the samples at $30 \%(\mathrm{w} / \mathrm{v})$ and the $\mathrm{pH}$ of the mixtures were set to 4.0. Then, $n$-butanol was added to each sample at an equal volume; samples were vigorously vortexed and left to rest for $1 \mathrm{~h}$ at RT, until the mixtures separated into three phases. The interfacial precipitate was collected in $1.5 \mathrm{~mL}$ microtubes, and re-suspended in $1 \mathrm{~mL}$ Tris $20 \mathrm{mM}+10 \mu \mathrm{L}$ protease inhibitor. Finally, samples were submitted to diafiltration and buffer exchange with $\mathrm{NH}_{4} \mathrm{HCO}_{3}(100 \mathrm{mM})$, using $5 \mathrm{kDa}$ cutoff spin columns (Millipore).

\section{In-solution tryptic digestion of TPP-extracted proteins}

Protein samples were resuspended in $1 \mathrm{~mL}$ of $0.1 \%$ Rapigest (Waters Corporation, Milford, MA) and concentrated using a $5 \mathrm{kDa}$ cut-off spin column. The solution was heated at $80^{\circ} \mathrm{C}$ for 15 minutes, reduced with dithiothreitol, alkylated with iodoacetamide and digested with 1:50 (w/w) sequencing grade trypsin for 16 hours. RapiGest was hydrolysed by the addition of $2 \mu \mathrm{L}$ of $13 \mathrm{M}$ trifluoroacetic acid, filtered using a $0.22 \mu \mathrm{m}$ spin column and each sample was typically diluted to $1 \mu \mathrm{g} /$ $\mu \mathrm{L}$ prior to a $1: 1$ dilution with a $100 \mathrm{fmol} / \mu \mathrm{L}$ glycogen phosphorylase B standard tryptic digest to give a final protein concentration of $500 \mathrm{ng} / \mu \mathrm{L}$ per sample and $50 \mathrm{fmol} / \mu \mathrm{L}$ phosphorylase B.

\section{LC-MS configurations for label-free analysis $\left(\mathrm{LC}-M S^{\mathrm{E}}\right.$ )}

Nanoscale LC separations of tryptic peptides for qualitative and quantitative multiplexed LC-MS analysis were performed with a nanoACQUITY system (Waters Corporation) using a Symmetry $\mathrm{C}_{18}$ trapping column (180 $\mu \mathrm{m} \times 20 \mathrm{~mm} 5 \mu \mathrm{m})$ and a $\mathrm{BEH} \mathrm{C}_{18}$ analytical column $(75 \mu \mathrm{m} \times 250 \mathrm{~mm} 1.7 \mu \mathrm{m})$. The composition of solvent A was $0.1 \%$ formic acid in water, and solvent B $(0.1 \%$ formic acid in acetonitrile). Each sample (total digested protein $0.5 \mu \mathrm{g}$ ) was applied to the trapping column and flushed with $0.1 \%$ solvent $B$ for 2 minutes at a flow rate of $15 \mu \mathrm{L} / \mathrm{min}$. Sample elution was performed at a flow rate of $250 \mathrm{~nL} / \mathrm{min}$ by increasing the organic solvent concentration from 3 to $40 \%$ B over $90 \mathrm{~min}$. Three technical replicate injections of the TPP-extracted 1002 sample and four technical replicates of the TPP-extracted C231 sample were used for subsequent data analysis in this study. These were from two biological cultures of each C. pseudotuberculosis stain.

The precursor ion masses and associated fragment ion spectra of the tryptic peptides were mass measured with a Q-ToF Ultima Global or Synapt HDMS mass spectrometer (Waters Corporation) directly coupled to the chromatographic system. The time-of-flight analyzers of both mass spectrometers were externally calibrated using the MS/MS spectrum from [Glu ${ }^{1}$ Fibrinopeptide B (human - Sigma Aldrich, UK) obtained from the doubly charged peptide ion at $m / z 785.8426$. The monoisotopic mass of the doubly charged species in MS mode was also used for post-acquisition data correction. The latter was delivered at $500 \mathrm{fmol} / \mu \mathrm{L}$ to the mass spectrometer via a NanoLockSpray interface using the auxiliary pump of a nanoACQUITY system at a flow rate of $500 \mathrm{~nL} / \mathrm{min}$, sampled every 60 seconds.

Accurate mass data were collected in data independent mode of acquisition by alternating the energy applied to the collision cell/s between a low and elevated energy state $\left(\mathrm{MS}^{\mathrm{E}}\right)$. The spectral acquisition scan rate was typically $0.9 \mathrm{~s}$ with a $0.1 \mathrm{~s}$ interscan delay. On the Synapt HDMS instrument in the low energy MS mode, data were collected at constant trap and transfer collision energies (CE) of $3 \mathrm{eV}$ and $1 \mathrm{eV}$ respectively. In elevated energy MS mode, the trap collision energy was ramped from $15 \mathrm{eV}$ to $30 \mathrm{eV}$ with the transfer collision energy at $10 \mathrm{eV}$. On the Ultima Global instrument a low energy of $6 \mathrm{eV}$ was applied to the collision cell, increasing from $6 \mathrm{eV}$ to $35 \mathrm{eV}$ in elevated MS mode.

\section{Data processing for label-free acquisitions $\left(M S^{\mathrm{E}}\right)$}

The LC-MS ${ }^{\mathrm{E}}$ data were processed using ProteinLynx Global Server v2.4 (Waters Corporation, Milford, MA) (see additional file 9). In brief, lockmass-corrected spectra are centroided, deisotoped, and charge-state-reduced to produce a single accurately mass measured monoisotopic mass for each peptide and the associated fragment ion. The initial correlation of a precursor and a potential fragment ion is achieved by means of time alignment. The detection and correlation principles for data independent, alternate scanning LC-MS ${ }^{\mathrm{E}}$ data have been described [14].

\section{Database searches}

All data were searched using PLGS v2.4 against a Corynebacterium pseudotuberculosis database (NCBI Genome Project ID: 40687 and 40875), released in November 2009, to which the glycogen phosphorylase B and trypsin sequences had been appended. The database was randomised within PLGS generating a new concatenated database consisting of the original sequences plus one additional sequence for each entry with identical composition but randomly scrambled residues. This database contained a total of 4314 entries. A fixed modification of carbamidomethyl-C was specified, and variable modifications included were acetyl N-terminus, deamidation $\mathrm{N}$, deamidation $\mathrm{Q}$ and oxidation $\mathrm{M}$. One missed trypsin cleavage site was permitted. 
For the $\mathrm{MS}^{\mathrm{E}}$ data, the time-based correlation applied in data processing is followed by a further correlation process during the database search that is based on the physicochemical properties of peptides when they undergo collision induced fragmentation. The precursor and fragment ion tolerances were determined automatically. The initial protein identification criteria used by the Identity ${ }^{\mathrm{E}}$ algorithm within PLGS for a single replicate data file, required the detection of at least three fragment ions per peptide, seven fragment ions and a minimum of one peptide per protein.

A process analogous to the Bayesian model described by Nesvizhskii et al. [79] was used by PLGS to assign probability values to scores of peptide and protein identifications. Two automated mechanisms determined peptide and protein threshold identification criteria providing a 95\% identification confidence interval. A background search is conducted by the search algorithm creating a discriminating decoy identification distribution. The determined peptide cut-off score, typically a $\log$ value of 6.25 for the expected 95\% identification probability is automatically applied to the results.

Further more stringent filtering was then applied to the database search results from each sample to improve the confidence in the protein observations and quantitative measurements. The results from each of the individual replicate analyses from each sample were combined and proteins were removed that were observed in only one of the replicates. Using this additional and rigorous filter the false discovery rate was further reduced to $0.2 \%$ for this study, with an average of 16.5 peptides/protein and $37.5 \%$ sequence coverage for the TPP-extracted 1002 sample and 15 peptides/protein with $35 \%$ sequence coverage for the respective C231 sample. Proteins were observed on average in 2.81 technical replicates in the 1002 sample where 3 replicate analyses were used and 3.52 for the C231 sample in which 4 replicates were included.

\section{Protein quantification using label-free system $\left(\mathrm{MS}^{\mathrm{E}}\right)$}

Relative quantitative analysis between samples was performed by comparing normalized peak area/intensity of each identified peptide [80]. For relative quantification, automatic normalization was applied to the data set within PLGS using the total peptide complement of each sample. The redundant, proteotypic quantitative measurements generated from the tryptic peptide identifications from each protein were used to determine an average, relative protein fold-change, with a confidence interval and a regulation probability. The confidently identified peptides to protein ratios were automatically weighted based on their identification probability. Binary comparisons were conducted to generate an average normalized intensity ratio for all matched proteins.
The entire data set of differentially expressed proteins was further filtered by considering only the identified proteins that replicated in at least two technical replicates with a score $>250$ and likelihood of regulation value greater than 0.95 for upregulation and lower than 0.05 for downregulation as determined by the PLGS quantification algorithm.

\section{In silico predictions of protein sub-cellular localization}

Prediction of sub-cellular localization was performed initially for the identified proteins by using the SurfG+ program v1.0, run locally in a Linux environment, as described [15] (see additional file 9). For prediction of potentially surface exposed (PSE) proteins, a cut-off value of 73 amino acids was calculated as the minimum distance from the C. pseudotuberculosis outermost membrane until the surface of the cell-wall, based on electron microscopy of this bacterium's cell envelope (data not shown).

The programs TatP v1.0 and SecretomeP v2.0 were used through the web applications available at http:// www.cbs.dtu.dk/services/, for prediction of twin-arginine pathway-linked signal peptides and non-classical (leaderless) secretion, respectively [29,81].

\section{Comparative analyses of multiple corynebacterial exoproteomes}

A list of experimentally observed extracellular proteins of pathogenic (C. diphtheriae and C. jeikeium) and nonpathogenic (C. glutamicum and C. efficiens) corynebacteria was identified in previously published studies $[17,37,64,65]$. The amino acid sequences of these proteins were retrieved from public repositories of protein sequences to create a local database. This database was used in similarity searches with the Blast-p algorithm $\left(\right.$ E-value $\left.<10^{-4}\right)[26]$, taking the group of proteins identified in the C. pseudotuberculosis exoproteome as the input sequences. Additionally, transitivity clustering [82] was used to identify proteins (i) commonly detected in the exoproteomes of pathogenic and non-pathogenic corynebacteria, and proteins detected in exoproteomes of (ii) only pathogenic corynebacteria or (iii) only C. pseudotuberculosis. A more detailed description on the transitivity clustering analysis can be found in the supplementary material (additional file 9). The amino acid sequences of the identified C. pseudotuberculosis exoproteins were also used in similarity searches against public databases, namely NCBI nr and Swissprot.

\section{Transcriptional regulation of the identified exoproteins}

The search for transcription factors that regulate expression of the identified corynebacterial exoproteins was performed through the CoryneRegNet database, as described previously [83]. 


\section{Accession numbers}

The sequences of all proteins identified in this work are accessible through GenBank and correspond to the Corynebacterium pseudotuberculosis Genome Projects deposited in NCBI (IDs: 40687 and 40875).

\section{Additional material}

Additional file 1: Figure S1. Comparison between the experimental (A) and virtual (B) 2-D gels of the exoproteome of the strain 1002 of C. pseudotuberculosis. (A) 2D-gel with $150 \mu \mathrm{g}$ of TPP extracted extracellular proteins of the 1002 strain. Proteins were separated in the first dimension by isoelectric focusing using strips of 3.0-5.6 NL pl range (GE Healthcare). Visualization was by Colloidal Coomassie staining. (B) The virtual 2D-gel was generated with the theoretical pl and MW values of the proteins identified by LC-MSE.

Additional file 2: Table S1. Proteins composing the core $C$. pseudotuberculosis exoproteome, identified by LC-MS .

Additional file 3: Table S2. Variant exoproteome of the strain 1002 of Corynebacterium pseudotuberculosis.

Additional file 4: Table S3. Variant exoproteome of the strain C231 of Corynebacterium pseudotuberculosis.

Additional file 5: Figure S2. Predictions of LPXTG motif-containing proteins, lipoproteins and Tat-pathway associated signal peptides in the exoproteomes of the strains 1002 and C231 of C. pseudotuberculosis.

Additional file 6: Figure S4. A conserved hypothetical exported protein present in the Genome of the strain C231 but absent from the strain 1002 of C. pseudotuberculosis. The two sequenced Genomes were aligned using the Artemis Comparison Tool (ACT). The arrows point to tRNA genes.

Additional file 7: Table S4. Relative expression analysis of the extracellular proteins common to the strains 1002 and C231 of Corynebacterium pseudotuberculosis.

Additional file 8: Figure S5. Distribution of orthologous proteins of the C. pseudotuberculosis experimental exoproteins throughout other experimentally confirmed exoproteomes of pathogenic corynebacteria, as determined through transitivity clustering analysis. The $19 \mathrm{C}$. pseudotuberculosis exoproteins only identified in the exoproteomes of other pathogenic corynebacteria are presented in the table. $C p=C$. pseudotuberculosis; $C d=C$. diphtheriae; $C j=C$. jeikeium.

Additional file 9: Supplementary information on the bioinformatics tools used in this study.

\section{List of abbreviations}

CDM: chemically defined medium; CLA: caseous lymphadenitis; LC-MS: liquid chromatography - mass spectrometry; NCS: non-classically secreted; PLD: phospholipase D; PLGS: ProteinLynx Global Server; PMF: peptide mass fingerprinting; PSE: potentially surface exposed; RGMG: Minas Gerais Genome Network; RPGP: Genome and Proteome Network of the State of Pará; TPP: Three-Phase Partitioning.

\section{Acknowledgements}

We are thankful to the Minas Gerais Genome Network (RGMG) and to the Genome and Proteome Network of the State of Pará (RPGP). We thank Dr. Robert Moore (CSIRO Livestock Industries) for providing the C231 strain of $C$. pseudotuberculosis.

This work was supported by grants from the Funding Agencies CNPq (grant CNPq/MAPA/SDA) and FAPEMIG, in Brazil; and by The Medical Research Fund and Advantage West Midlands, in the UK.

\section{Author details}

'Department of Biochemistry and Immunology, Instituto de Ciências Biológicas, Universidade Federal de Minas Gerais, Av. Antônio Carlos, Belo Horizonte, 31.270-901, Brazil. ${ }^{2}$ Department of General Biology, Instituto de Ciências Biológicas, Universidade Federal de Minas Gerais, Av. Antônio Carlos, Belo Horizonte, 31.270-901, Brazil. Institute of Health Sciences, Universidade Federal da Bahia, Av. Reitor Miguel Calmon, Salvador, 40.110902, Brazil. ${ }^{4}$ School of Life Sciences, University of Warwick, Gibbet Hill Road, Coventry, CV4 7AL, United Kingdom. ${ }^{5}$ Department of Microbiology, Instituto de Ciências Biológicas, Universidade Federal de Minas Gerais, Av. Antônio Carlos, Belo Horizonte, 31.270-901, Brazil. ${ }^{6}$ Genome and Proteome Network of the State of Pará, Universidade Federal do Pará, R. Augusto Corrêa, Belém, 66.075-110, Brazil.

\section{Authors' contributions}

LGCP, SES, LMF, MARC, AMCP, RM, AS, JHS, SCO, AM, CGD, and VA conceived the idea, participated in the design of the study, and critically read the manuscript. LGCP, SES, NS, TLPC, WMS, AGV, and SGS performed microbiological and/or proteomic experiments. LGCP, SES and ARS performed bioinformatical analyses. LGCP and SES wrote the manuscript. All authors read and approved the final manuscript.

\section{Competing interests}

The authors declare that they have no competing interests.

Received: 15 October 2010 Accepted: 17 January 2011

Published: 17 January 2011

\section{References}

1. Dorella FA, Pacheco LGC, Oliveira SC, Miyoshi A, Azevedo V: Corynebacterium pseudotuberculosis: microbiology, biochemical properties, pathogenesis and molecular studies of virulence. Vet Res 2006, 37:201-218.

2. Ventura M, Canchaya C, Tauch A, Chandra G, Fitzgerald GF, Chater KF, van Sinderen D: Genomics of Actinobacteria: tracing the evolutionary history of an ancient phylum. Microbiol Mol Biol Rev 2007, 71:495-548.

3. Baird GJ, Fontaine MC: Corynebacterium pseudotuberculosis and its role in ovine caseous lymphadenitis. J Comp Pathol 2007, 137:179-210.

4. Dorella FA, Pacheco LG, Seyffert N, Portela RW, Meyer R, Miyoshi A, Azevedo V: Antigens of Corynebacterium pseudotuberculosis and prospects for vaccine development. Expert Rev Vaccines 2009, 8:205-213.

5. Hodgson AL, Bird P, Nisbet IT: Cloning, nucleotide sequence, and expression in Escherichia coli of the phospholipase D gene from Corynebacterium pseudotuberculosis. J Bacteriol 1990, 172:1256-1261.

6. Billington SJ, Esmay PA, Songer JG, Jost BH: Identification and role in virulence of putative iron acquisition genes from Corynebacterium pseudotuberculosis. FEMS Microbiol Lett 2002, 208:41-45.

7. Desvaux M, Hébraud M, Talon R, Henderson IR: Secretion and subcellular localizations of bacterial proteins: a semantic awareness issue. Trends Microbiol 2009, 17:139-145.

8. Bhavsar AP, Guttman JA, Finlay BB: Manipulation of host-cell pathways by bacterial pathogens. Nature 2007, 449:827-834.

9. Stavrinides J, McCann HC, Guttman DS: Host-pathogen interplay and the evolution of bacterial effectors. Cell Microbiol 2008, 10:285-292.

10. Sibbald MJJB, van Dij JML: Secretome Mapping in Gram-Positive Pathogens. In Bacterial secreted protein: secretory mechanisms and role in pathogenesis Edited by: Karl Wooldridge 2009, 193-225.

11. Paule BJA, Meyer R, Moura-Costa LF, Bahia RC, Carminati R, Regis LF, Vale VLC, Freire SM, Nascimento I, Schaer R, Azevedo V: Three-phase partitioning as an efficient method for extraction/concentration of immunoreactive excreted-secreted proteins of Corynebacterium pseudotuberculosis. Protein Expr Purif 2004, 34:311-316.

12. Dorella FA, Estevam EM, Pacheco LGC, Guimarães CT, Lana UGP, Gomes EA, Barsante MM, Oliveira SC, Meyer R, Miyoshi A, Azevedo V: In vivo insertional mutagenesis in Corynebacterium pseudotuberculosis: an efficient means to identify DNA sequences encoding exported proteins. Appl Environ Microbiol 2006, 72:7368-7372. 
13. Silva JC, Gorenstein MV, Li G, Vissers JPC, Geromanos SJ: Absolute quantification of proteins by LCMSE a virtue of parallel MS acquisition. Mol Cell Proteomics 2006, 5:144-156.

14. Geromanos SJ, Vissers JPC, Silva JC, Dorschel CA, Li G, Gorenstein MV, Bateman RH, Langridge Jl: The detection, correlation, and comparison of peptide precursor and product ions from data independent LC-MS with data dependant LC-MS/MS. Proteomics 2009, 9:1683-1695.

15. Barinov A, Loux V, Hammani A, Nicolas P, Langella P, Ehrlich D, Maguin E, van de Guchte M: Prediction of surface exposed proteins in Streptococcus pyogenes, with a potential application to other Gram-positive bacteria. Proteomics 2009, 9:61-73.

16. Trost $M$, Wehmhöner $D$, Kärst $U$, Dieterich $G$, Wehland J, Jänsch L: Comparative proteome analysis of secretory proteins from pathogenic and nonpathogenic Listeria species. Proteomics 2005, 5:1544-1557.

17. Hansmeier N, Chao T, Kalinowski J, Pühler A, Tauch A: Mapping and comprehensive analysis of the extracellular and cell surface proteome of the human pathogen Corynebacterium diphtheriae. Proteomics 2006, 6:2465-2476.

18. Målen H, Berven FS, Fladmark KE, Wiker HG: Comprehensive analysis of exported proteins from Mycobacterium tuberculosis H37Rv. Proteomics 2007, 7:1702-1718.

19. Mastronunzio JE, Huang Y, Benson DR: Diminished exoproteome of Frankia spp. in culture and symbiosis. Appl Environ Microbiol 2009, 75:6721-6728

20. Dumas E, Desvaux M, Chambon C, Hébraud M: Insight into the core and variant exoproteomes of Listeria monocytogenes species by comparative subproteomic analysis. Proteomics 2009, 9:3136-3155.

21. Hecker M, Reder A, Fuchs S, Pagels M, Engelmann S: Physiological proteomics and stress/starvation responses in Bacillus subtilis and Staphylococcus aureus. Res Microbiol 2009, 160:245-258.

22. Becher D, Hempel $K$, Sievers $S$, Zühlke D, Pané-Farré J, Otto A, Fuchs $S$, Albrecht D, Bernhardt J, Engelmann S, Völker U, van Dijl JM, Hecker M: A proteomic view of an important human pathogen-towards the quantification of the entire Staphylococcus aureus proteome. PLoS One 2009, 4:e8176.

23. Ribeiro OC, Silva JAH, Oliveira SC, Meyer R, Fernandes GB: Preliminary results on a living vaccince against caseous lymphadenitis. Pesquisa Agropecuaria Brasileira 1991, 26:461-465.

24. Simmons CP, Dunstan SJ, Tachedjian M, Krywult J, Hodgson AL, Strugnell RA: Vaccine potential of attenuated mutants of Corynebacterium pseudotuberculosis in sheep. Infect Immun 1998, 66:474-479.

25. Patel VJ, Thalassinos K, Slade SE, Connolly JB, Crombie A, Murrell JC, Scrivens $\mathrm{JH}$ : A comparison of labeling and label-free mass spectrometrybased proteomics approaches. J Proteome Res 2009, 8:3752-3759.

26. Altschul SF, Gish W, Miller W, Myers EW, Lipman DJ: Basic local alignment search tool. J Mol Biol 1990, 215:403-410.

27. Khamis A, Raoult D, La Scola B: rpoB gene sequencing for identification of Corynebacterium species. J Clin Microbiol 2004, 42:3925-3931.

28. Altschul SF, Madden TL, Schäffer AA, Zhang J, Zhang Z, Miller W, Lipman DJ: Gapped BLAST and PSI-BLAST: a new generation of protein database search programs. Nucleic Acids Res 1997, 25:3389-3402.

29. Bendtsen JD, Kiemer L, Fausbø\|l A, Brunak S: Non-classical protein secretion in bacteria. BMC Microbiol 2005, 5:58.

30. Vanet A, Labigne A: Evidence for specific secretion rather than autolysis in the release of some Helicobacter pylori proteins. Infect Immun 1998, 66:1023-1027.

31. Bendtsen JD, Wooldridge KG: Non-Classical Secretion. In Bacterial secreted proteins: secretory mechanisms and role in pathogenesis Edited by: Karl Wooldridge 2009, 225-239.

32. Jeffery CJ: Moonlighting proteins-an update. Mol Biosyst 2009, 5:345-350.

33. Rodríguez-Ortega MJ, Norais N, Bensi G, Liberatori S, Capo S, Mora M, Scarselli M, Doro F, Ferrari G, Garaguso I, Maggi T, Neumann A, Covre A, Telford $J \mathrm{~L}$, Grandi G: Characterization and identification of vaccine candidate proteins through analysis of the group A Streptococcus surface proteome. Nat Biotechnol 2006, 24:191-197.

34. Doro F, Liberatori S, Rodríguez-Ortega MJ, Rinaudo CD, Rosini R, Mora M, Scarselli M, Altindis E, D'Aurizio R, Stella M, Margarit I, Maione D, Telford JL, Norais N, Grandi G: Surfome analysis as a fast track to vaccine discovery: identification of a novel protective antigen for Group B Streptococcus hypervirulent strain COH1. Mol Cell Proteomics 2009, 8:1728-1737.
35. Barbey C, Budin-Verneuil A, Cauchard S, Hartke A, Laugier C, Pichereau V, Petry S: Proteomic analysis and immunogenicity of secreted proteins from Rhodococcus equi ATCC 33701. Vet Microbiol 2009, 135:334-345.

36. Hecker M, Becher D, Fuchs S, Engelmann S: A proteomic view of cell physiology and virulence of Staphylococcus aureus. Int J Med Microbiol 2010, 300:76-87.

37. Hansmeier N, Chao T, Pühler A, Tauch A, Kalinowski J: The cytosolic, cell surface and extracellular proteomes of the biotechnologically important soil bacterium Corynebacterium efficiens YS-314 in comparison to those of Corynebacterium glutamicum ATCC 13032. Proteomics 2006, 6:233-250.

38. Schaumburg J, Diekmann O, Hagendorff P, Bergmann S, Rohde M, Hammerschmidt S, Jänsch L, Wehland J, Kärst U: The cell wall subproteome of Listeria monocytogenes. Proteomics 2004, 4:2991-3006.

39. Sibbald MJJB, Ziebandt AK, Engelmann S, Hecker M, de Jong A, Harmsen HJM, Raangs GC, Stokroos I, Arends JP, Dubois JYF, van Dijl JM: Mapping the pathways to staphylococcal pathogenesis by comparative secretomics. Microbiol Mol Biol Rev 2006, 70:755-788.

40. Furuya $H$, Ikeda $\mathrm{R}$ : Interaction of triosephosphate isomerase from the cell surface of Staphylococcus aureus and alpha-(1->3)mannooligosaccharides derived from glucuronoxylomannan of Cryptococcus neoformans. Microbiology 2009, 155:2707-2713.

41. Söderberg MA, Cianciotto NP: A Legionella pneumophila peptidyl-prolyl cis-trans isomerase present in culture supernatants is necessary for optimal growth at low temperatures. Appl Environ Microbiol 2008, 74:1634-1638

42. Kunert A, Losse J, Gruszin C, Hühn M, Kaendler K, Mikkat S, Volke D, Hoffmann R, Jokiranta TS, Seeberger H, Moellmann U, Hellwage J, Zipfel PF: Immune evasion of the human pathogen Pseudomonas aeruginosa: elongation factor Tuf is a factor $\mathrm{H}$ and plasminogen binding protein. $J$ Immunol 2007, 179:2979-2988.

43. Tsugawa H, Ito H, Ohshima M, Okawa Y: Cell adherence-promoted activity of Plesiomonas shigelloides groEL. J Med Microbiol 2007, 56:23-29.

44. Feng Y, Pan X, Sun W, Wang C, Zhang H, Li X, Ma Y, Shao Z, Ge J, Zheng F, Gao GF, Tang J: Streptococcus suis enolase functions as a protective antigen displayed on the bacterial cell surface. J Infect Dis 2009, 200:1583-1592.

45. Pissavin C, Hugouvieux-Cotte-Pattat N: Characterization of a periplasmic peptidyl-prolyl cis-trans isomerase in Erwinia chrysanthemi. FEMS Microbiol Lett 1997, 157:59-65.

46. Bergonzelli GE, Granato D, Pridmore RD, Marvin-Guy LF, Donnicola D, Corthésy-Theulaz IE: GroEL of Lactobacillus johnsonii La1 (NCC 533) is cell surface associated: potential role in interactions with the host and the gastric pathogen Helicobacter pylori. Infect Immun 2006, 74:425-434.

47. He X, Zhuang Y, Zhang X, Li G: Comparative proteome analysis of culture supernatant proteins of Mycobacterium tuberculosis H37Rv and H37Ra. Microbes Infect 2003, 5:851-856.

48. Sumby P, Whitney AR, Graviss EA, DeLeo FR, Musser JM: Genome-wide analysis of group a streptococci reveals a mutation that modulates global phenotype and disease specificity. PLoS Pathog 2006, 2:e5.

49. Dumas E, Meunier B, Berdagué J, Chambon C, Desvaux M, Hébraud M: Comparative analysis of extracellular and intracellular proteomes of Listeria monocytogenes strains reveals a correlation between protein expression and serovar. Appl Environ Microbiol 2008, 74:7399-7409.

50. van der Woude MW, Bäumler AJ: Phase and antigenic variation in bacteria. Clin Microbiol Rev 2004, 17:581-611, table of contents.

51. Behr MA, Sherman DR: Mycobacterial virulence and specialized secretion: same story, different ending. Nat Med 2007, 13:286-287.

52. McKean SC, Davies JK, Moore RJ: Expression of phospholipase D the major virulence factor of Corynebacterium pseudotuberculosis, is regulated by multiple environmental factors and plays a role in macrophage death. Microbiology 2007, 153:2203-2211.

53. Hodgson AL, Krywult J, Corner LA, Rothel JS, Radford AJ: Rational attenuation of Corynebacterium pseudotuberculosis: potential cheesy gland vaccine and live delivery vehicle. Infect Immun 1992, 60:2900-2905.

54. McNamara PJ, Bradley GA, Songer JG: Targeted mutagenesis of the phospholipase $D$ gene results in decreased virulence of Corynebacterium pseudotuberculosis. Mol Microbiol 1994, 12:921-930.

55. Moore RJ, Rothel L, Krywult J, Radford AJ, Lund K, Hodgson AL: Foreign gene expression in Corynebacterium pseudotuberculosis: development of a live vaccine vector. Vaccine 1999, 18:487-497. 
56. Meyer R, Carminati R, Bahia R, Vale V, Viegas $S$, Martinez T, Nascimento I, Schaer R, Silva J, Ribeiro M, Regis L, Paule B, Freire S: Evaluation of the goats humoral immune response induced by the Corynebacterium pseudotuberculosis lyophilized live vaccine. J Med Biol Sci 2002, 1:42-48,

57. Walker J, Jackson HJ, Eggleton DG, Meeusen EN, Wilson MJ, Brandon MR: Identification of a novel antigen from Corynebacterium pseudotuberculosis that protects sheep against caseous lymphadenitis. Infect Immun 1994, 62:2562-2567.

58. Koonin EV, Makarova KS, Aravind L: Horizontal gene transfer in prokaryotes: quantification and classification. Annu Rev Microbiol 2001, 55:709-742.

59. Nogueira T, Rankin DJ, Touchon M, Taddei F, Brown SP, Rocha EPC: Horizontal gene transfer of the secretome drives the evolution of bacterial cooperation and virulence. Curr Biol 2009, 19:1683-1691.

60. Hett EC, Rubin EJ: Bacterial growth and cell division: a mycobacterial perspective. Microbiol Mol Biol Rev 2008, 72:126-56, table of contents.

61. Allen CE, Schmitt MP: HtaA is an iron-regulated hemin binding protein involved in the utilization of heme iron in Corynebacterium diphtheriae. $J$ Bacteriol 2009, 191:2638-2648

62. Puech V, Chami M, Lemassu A, Lanéelle MA, Schiffler B, Gounon P, Bayan N, Benz R, Daffé M: Structure of the cell envelope of corynebacteria: importance of the non-covalently bound lipids in the formation of the cell wall permeability barrier and fracture plane. Microbiology 2001, 147:1365-1382.

63. Jordan S, Hutchings Ml, Mascher T: Cell envelope stress response in Gram-positive bacteria. FEMS Microbiol Rev 2008, 32:107-146.

64. Hansmeier N, Chao T, Daschkey S, Müsken M, Kalinowski J, Pühler A, Tauch A: A comprehensive proteome map of the lipid-requiring nosocomial pathogen Corynebacterium jeikeium K411. Proteomics 2007, 7:1076-1096

65. Suzuki N, Watanabe K, Okibe N, Tsuchida Y, Inui M, Yukawa H: Identification of new secreted proteins and secretion of heterologous amylase by C. glutamicum. Appl Microbiol Biotechnol 2009, 82:491-500.

66. Hartmann M, Barsch A, Niehaus K, Pühler A, Tauch A, Kalinowski J: The glycosylated cell surface protein $\mathrm{Rpf} 2$, containing a resuscitationpromoting factor motif, is involved in intercellular communication of Corynebacterium glutamicum. Arch Microbiol 2004, 182:299-312.

67. Sakamoto J, Shibata T, Mine T, Miyahara R, Torigoe T, Noguchi S, Matsushita K, Sone N: Cytochrome c oxidase contains an extra charged amino acid cluster in a new type of respiratory chain in the amino-acidproducing Gram-positive bacterium Corynebacterium glutamicum. Microbiology 2001, 147:2865-2871.

68. Tsuge $Y$, Ogino $H$, Teramoto $H$, Inui $M$, Yukawa H: Deletion of cgR_1596 and cgR_2070, encoding NIpC/P60 proteins, causes a defect in cell separation in Corynebacterium glutamicum R. J Bacteriol 2008 190:8204-8214.

69. Körner H, Sofia HJ, Zumft WG: Phylogeny of the bacterial superfamily of Crp-Fnr transcription regulators: exploiting the metabolic spectrum by controlling alternative gene programs. FEMS Microbiol Rev 2003, 27:559-592.

70. Oram D, Avdalovic A, Holmes R: Analysis of genes that encode DtxR-like transcriptional regulators in pathogenic and saprophytic corynebacterial species. Infect Immun 2004, 72:1885-1895.

71. Kohl T, Baumbach J, Jungwirth B, Puhler A, Tauch A: The GlxR regulon of the amino acid producer Corynebacterium glutamicum: in silico and in vitro detection of DNA binding sites of a global transcription regulator. $J$ Biotechnol 2008, 135:340-350.

72. Stubben CJ, Duffield ML, Cooper IA, Ford DC, Gans JD, Karlyshev AV, Lingard B, Oyston PCF, de Rochefort A, Song J, Wren BW, Titball RW, Wolinsky M: Steps toward broad-spectrum therapeutics: discovering virulence-associated genes present in diverse human pathogens. BMC Genomics 2009, 10:501.

73. Janson H, Melhus A, Hermansson A, Forsgren A: Protein D the glycerophosphodiester phosphodiesterase from Haemophilus influenzae with affinity for human immunoglobulin $D$ influences virulence in a rat otitis model. Infect Immun 1994, 62:4848-4854

74. Braun V: Iron uptake mechanisms and their regulation in pathogenic bacteria. Int J Med Microbiol 2001, 291:67-79.

75. Roe MR, Griffin TJ: Gel-free mass spectrometry-based high throughput proteomics: tools for studying biological response of proteins and proteomes. Proteomics 2006, 6:4678-4687.
76. Panchaud A, Affolter M, Moreillon P, Kussmann M: Experimental and computational approaches to quantitative proteomics: status quo and outlook. J Proteomics 2008, 71:19-33.

77. Pacheco LGC, Pena RR, Castro TLP, Dorella FA, Bahia RC, Carminati R, Frota MNL, Oliveira SC, Meyer R, Alves FSF, Miyoshi A, Azevedo V: Multiplex PCR assay for identification of Corynebacterium pseudotuberculosis from pure cultures and for rapid detection of this pathogen in clinical samples. J Med Microbiol 2007, 56:480-486.

78. Moura-Costa LF, Paule BJA, Azevedo V, Freire SM, Nascimento I, Schaer R, Regis LF, Vale VLC, Matos DP, Bahia RC, Carminati R, Meyer R: Chemically defined synthetic medium for Corynebacterium pseudotuberculosis culture. Rev. Bras. Saúde e Produção Animal 2002, 3:1-9.

79. Nesvizhskii Al, Keller A, Kolker E, Aebersold R: A statistical model for identifying proteins by tandem mass spectrometry. Anal Chem 2003, 75:4646-4658.

80. Silva JC, Denny R, Dorschel CA, Gorenstein M, Kass IJ, Li G, McKenna T, Nold MJ, Richardson K, Young P, Geromanos S: Quantitative proteomic analysis by accurate mass retention time pairs. Anal Chem 2005, 77:2187-2200.

81. Bendtsen JD, Nielsen H, Widdick D, Palmer T, Brunak S: Prediction of twinarginine signal peptides. BMC Bioinformatics 2005, 6:167

82. Wittkop T, Emig D, Lange S, Rahmann S, Albrecht M, Morris JH, Böcker S, Stoye J, Baumbach J: Partitioning biological data with transitivity clustering. Nat Methods 2010, 7:419-420.

83. Baumbach J, Wittkop T, Kleindt CK, Tauch A: Integrated analysis and reconstruction of microbial transcriptional gene regulatory networks using CoryneRegNet. Nat Protoc 2009, 4:992-1005.

84. Götz S, García-Gómez JM, Terol J, Williams TD, Nagaraj SH, Nueda MJ, Robles M, Talón M, Dopazo J, Conesa A: High-throughput functional annotation and data mining with the Blast2GO suite. Nucleic Acids Res 2008, 36:3420-3435.

doi:10.1186/1471-2180-11-12

Cite this article as: Pacheco et al: A combined approach for comparative exoproteome analysis of Corynebacterium pseudotuberculosis. BMC Microbiology 2011 11:12.

\section{Submit your next manuscript to BioMed Central and take full advantage of:}

- Convenient online submission

- Thorough peer review

- No space constraints or color figure charges

- Immediate publication on acceptance

- Inclusion in PubMed, CAS, Scopus and Google Scholar

- Research which is freely available for redistribution

Submit your manuscript at www.biomedcentral.com/submit
C Biomed Central 